\title{
1. Why study leadership from a philosophical perspective?
}

I would like to beg you, dear Sir, as well as I can to have patience with everything unresolved in your heart and to try to love the questions themselves as if they were locked rooms or books written in a very foreign language ... Live the questions now. Perhaps then, someday far in the future, you will gradually, without even noticing it, live your way to the answer.

Rainer Maria Rilke Letters to a Young Poet (1929 [2009], p. 35)

Why are there so many different theories of leadership? In fact, what is leadership? Sociology, anthropology, political science and psychology are among the disciplines which have addressed these questions. Definitive answers, however, remain elusive. Rather than attempting to provide such answers, this book questions the very questions perennially asked about leadership. In it ideas from the branch of philosophy known as 'Continental philosophy' are applied to interrogate habitual ways of thinking about and inquiring into this much studied phenomenon. For instance, rather than asking 'What is leadership?', the question, 'How might we understand leadership as a phenomenon?' is posed. Rather than wondering, 'Why aren't there more women in senior leadership roles?' the question, 'Why is gender so important in leadership?' will be explored. Through 'living the questions' differently and living different questions, this book aspires to breathe new life into the way scholars, teachers and students intrigued by it might re-conceptualize leadership and its role in human communities.

Continental philosophy has never been wary of engaging with the significant questions of purpose and meaning central to human life. In this second edition of the book I extend beyond phenomenology to include Michel Foucault's ideas about power and consider how they might inform our understanding of how power works within leadership relations. A further four new chapters are included, each of which has been written by a colleague who has extended ideas introduced in the original edition. These include a chapter on responsible leadership by Rita A. Gardiner, gender and leadership by Claire O'Neill, applying the leadership moment within contexts by Tayo Switzer and the 
importance of 'incompleteness' within leadership written by Perttu Salovaara. Concepts from phenomenology such as 'The Lifeworld', 'ready-to-hand' and 'flesh' are still elaborated upon as they serve as key underpinnings for philosophical insights offered throughout the text.

The book is designed for readers who are eager to explore alternative ways of thinking about leadership and the questions we ask about it. You do not need to have been philosophically trained to follow the arguments made here but you will need to engage with an open and curious mind. This introduction serves both to sketch the terrain the book covers, and to orient you to a way of thinking and reflecting which will be echoed throughout the text. To start, let us address the questions, 'Why yet another book about leadership?' and, 'How is this one different from the hundreds of other books you could choose to read?'

\section{WHY ANOTHER BOOK ABOUT LEADERSHIP?}

One thing that is clear about the leadership literature is that there is relatively little that is clear about leadership! ${ }^{2}$ Rather than despairing about the lack of definitional clarity, however, this book differs from many texts in that it invites you to consider the very 'indefinability' of leadership as significant. Does the lack of agreement amongst the hundreds of scholars who have written about this phenomenon itself hint at something essential about it? Considering leadership as a socially constructed phenomenon constituted by different people in particular circumstances provides some explanation for its lack of definitional edge. Rather than being satisfied with this explanation, this book interrogates such terrain more deeply and introduces ideas and modes of reflection which push the limits of current conceptualizations of both 'leaders' and 'leadership'.

In fact, the importance of drawing a distinction between 'leaders' and 'leadership' is a theme which runs throughout the book. Whereas many texts conflate the two terms, from a phenomenological perspective the difference between them is significant and even more noteworthy than the traditionally accepted polarization between 'leaders' and 'followers'. Similarly, rather than regarding leaders as central to organizational activities such as 'managing change' or 'sense-making', these processes themselves are closely examined and re-conceptualized, resulting in a different understanding of the role of 'leadership' in their occurrence. These are just a few examples of how this text aims to destabilize and reposition some of the more habitually held notions within this arena to propose a truly radical view.

First and foremost then, this book challenges us to re-examine the very questions we ask about leadership. In doing so, it aspires to stretch the leadership debate into areas not often considered within current theorizing. In my role as a faculty member of Antioch University's $\mathrm{PhD}$ in Leadership and Change 
Program I work with experienced professionals who are exploring how leadership can make a positive difference in their organizational contexts. Whether they are working in healthcare, education, third sector concerns or business, supporting them as they interweave the theory and practice of leading to tackle truly wicked problems always leaves me humbled. Furthermore, the continually changing nature of the challenges they face convinces me we have not finished asking all of the questions that need to be pursued about leadership and its importance for human communities. Although this book is primarily written for students of leadership, my hope is that much of what is offered here has practical implications for those who find themselves questioning how they might lead more effectively as part of their organizational roles.

\section{WHY DO THE QUESTIONS MATTER?}

As mentioned above, pursuing leadership from a philosophical standpoint invites us to reformulate the way we inquire into it. For instance, the question 'What is leadership?', shifts into the more philosophically oriented query, 'What kind of phenomenon is leadership?' This may seem only an inconsequential matter of semantics. However, if you pause and think about it, you will notice that each question evokes a different kind of response.

The question, 'What is leadership?' assumes the possibility of defining leadership in an objectively determined, clear-cut way, perhaps as one might be able to define a 'bird' or a 'fork-lift truck'. Such a question suggests that we can 'report it as we see it' and that doing so is a straightforward endeavor. The lack of agreement from so many scholars, leadership developers and organizational theorists who offer different (although often similar) definitions of the term, would seem to indicate the task of defining leadership is not so easy.

By posing the query, 'What kind of phenomenon is leadership?', the certainty that leadership is the kind of thing which can be described in a definitive way loses some of its power. Depending on the kind of phenomenon leadership is, the way we go about defining it may be altered. For instance, phenomena such as 'love' or 'justice' may be difficult to define and do not lend themselves to the same kind of analysis as do objects such as a 'bird' or a 'fork-lift truck'. Lack of definitional clarity does not imply that 'love' or 'justice' does not exist. However, because of their nature as phenomena, the way we go about defining them needs to be carefully considered.

Following from this, the query, 'What kind of phenomenon is leadership?' informs the question 'What is leadership?' Once we are clearer about its nature, we are better equipped to ponder what it might 'be'. The appropriateness of the question itself may come under scrutiny. As many philosophers have pointed out, the nature of the questions asked reveals different aspects of the phenomenon being examined. In this way, I am suggesting that philosoph- 
ical preoccupation with questioning the questions offers a way of expanding thinking into previously unexplored territories. Attending to the questions also raises issues of how they might best be pursued once they are discovered.

\section{What is the Relationship Between the Questions we ask and our Methods for Answering Them?}

The great majority of Western-based leadership theories are derived from research methods based in positivistic ways of knowing. In particular, the assumption that the approach used in the physical sciences can apply to examining leadership is witnessed by the large number of studies aimed at identifying particular leadership characteristics, traits or competencies. In this way, leadership is 'broken down' into its component parts and then, taking this method to its logical conclusion, those traits, characteristics or competencies are measured using a variety of psychometric or ideographic indicators.

An ideal example of this is 'transformational leadership', a popular leadership theory since its introduction by James MacGregor Burns (1978). Bernard Bass developed Burns' ideas in particular by identifying four attributes of transformational leaders: charisma, inspiration, individualized consideration and intellectual stimulation (Bass 1985). These four components can then be measured through the 'Transformational Leadership Questionnaire', an instrument developed by Beverley Alimo-Metcalfe and Robert Alban Metcalfe (2001), which assesses aspiring leaders' transformational capacities based on self-reported and 360 degree feedback measures. Having identified their strengths and weaknesses in terms of this quotient, potential leaders can create a 'development plan', to improve their performance on specific factors. There is a neatness about such an approach which is highly attractive. Like a car engine registering 'low' on oil or water, once identified deficient attributes can be 'topped up'.

Under closer examination, such an approach can be seen to have a number of limitations. Firstly, it collapses 'leadership', a collective process which encompasses not only leaders but their followers and the context in which they come into contact, into 'leaders', an individually based unit of analysis. In particular, the assumption that the approach used in studying the physical sciences can be applied to leadership is demonstrated by the large number of studies devoted to identifying leadership's 'parts' and measuring them using psychometric or ideographic indicators. However a normalized amount of idealized consideration may not be appropriate in every situation or organizational culture. What might be the perfect amount of individual consideration in an automobile factory might be entirely inappropriate within a university department. $^{3}$ 
Secondly, by isolating particular variables in this way, such approaches can fool us into thinking the ingredients which constitute an entity are all that are required to create the entity. A cake results from combining flour, sugar, butter and eggs but its production depends on the type of oven in which it is baked and even the altitude at which it is cooked. Although from a natural science standpoint it may be possible to identify and measure all such factors, those approaches would still not be able to account for the 'meaning' attributed to the cake by those who eat it. The significance of a cake used as the central focus of a birthday celebration differs from that of one tucked into a rucksack for sustenance on a hiking trip. Additionally, the 'success' of a cake will be judged differently depending on its purpose: the lopsided gift proudly offered by my 6-year-old niece will be judged differently from a misshapen delivery from a cake company I hired to produce the centerpiece at my wedding. Likewise, the effectiveness of any act of leading will be judged from within particular social and historical moments. Reductionist methods are ill-equipped to provide adequate insight into how leadership arises from such particularized instances.

There is a growing body of literature which similarly calls into question accounts which attempt to identify individually based traits or even individually initiated actions which alone constitute 'leadership'. Building on the earlier work of Cecil Gibb (1954), Peter Gronn's (2000) ideas about 'distributed leadership' contest the possibility of identifying individual leaders and measuring the level of impact they have on any task's achievement. Writers such as Amanda Sinclair (1994, 2005b) and Mary Uhl-Bien (2006) bring to our attention the more relational and 'invisible' aspects of leadership which do not lend themselves to clear identification and quantification. This second edition of Rethinking Leadership extends the broader post-positivist conversation by bringing a philosophically informed angle to the debate, as well as building on ideas introduced in the first edition.

\section{WHY PHILOSOPHY?}

How might philosophy contribute to our thinking about leadership in ways other disciplines have not already attempted? In her introduction to the special issue of the Leadership Quarterly devoted to 'Leadership and the Humanities', Joanne Ciulla (2008) suggests 'leadership is a human phenomenon embedded in culture, which includes art, literature, religion, philosophy, language and generally all those things that constitute what it means to live as a human being' (p. 393). As a philosopher herself, she then traces the line of philosophers from the classical thinker Giambattista Vico (1668-1744) through to post-positivists such as Michel Foucault (1926-1984), who have laid the tracks in developing humanities-based ways of developing and verifying knowing. 
Ciulla argues that both social sciences, with their focus on deconstruction and correlation, and the humanities, with their attention to holistic understanding and reliance on human capacities for story-telling, use of metaphor and image in their sense-making processes need to be incorporated to come to a fuller understanding of a phenomenon such as leadership.

Philosophy, like psychology or sociology, is not a unified body of ideas and approaches. As indicated earlier, in this book I draw from a range of ideas located under the broad umbrella of Continental philosophy developed largely in Europe from the beginning of the twentieth century. The primary strand of Continental philosophy which informs the text is phenomenology, a 'family group' of ideas which have their genesis in the work of Edmund Husserl (1859-1938). ${ }^{4}$ As we will see in Chapter 2, one of phenomenology's key projects is to reclaim the validity of epistemologies more associated with philosophy than science, especially in developing truths about the everyday world of human beings.

In particular, phenomenology recognizes the subjective nature of knowledge and pays close attention to lived experience as a valid source of knowing. Many of the more traditional ways of exploring leadership attempt to describe it 'from the outside' in accordance with accepted social science methods and assumptions about validity and objectivity. In contrast, phenomenology embraces the significance of meaning within human sense-making processes. Concerned with aspects of quality rather than quantity, it reasserts the importance of felt experience as well as the cumulative effects of history on our ability to know. Additionally, it recognizes the impact of absent or invisible aspects of an entity as well as explicitly present ones and in so doing alerts us to the possibility that when exploring a phenomenon such as leadership, what one does not see may be as important as what one does see.

As the qualitative, experienced and absent aspects of phenomena are impossible to identify, measure and correlate, they have largely been ignored by social scientists intent on defining, assessing and manipulating leadership. Phenomenology provides a language and an approach which allows access into these emergent and obscure territories. In this way, it may not arrive at definitive answers to questions such as "How much "individual consideration" does it take to produce a transformational leader?' However, it does offer a set of concepts which enable the experience of transformational leadership to be pondered in a more complex and multi-dimensional way. Particularly, phenomenology brings the experience of whoever is being led directly into the center of what constitutes leadership. In this way its very aim prohibits thinking of 'leadership' primarily in terms of 'leaders'.

Stepping back from the specific concerns of phenomenology momentarily, let us consider the question 'Why engage philosophy to study leadership?' more broadly. The word 'philosophy' has its roots in the Greek philosophia 
which is often translated as 'lover of wisdom'. We have come to understand philosophy both as a body of writing which addresses the fundamental questions of the human condition (for example, 'What is the meaning of life?'; 'What is my purpose?'; 'How should I balance my own needs with those of others?') as well as a method for thinking about those questions. In this book, philosophy is used in both ways. Firstly, particular philosophical ideas will be introduced which I hope will provide you with new vantage points from which to regard and expand your habitually held views about leadership.

Secondly, throughout the book the use of a potent philosophical tool, inquiry, will be modeled. As I hope may already be apparent, philosophers take the business of asking questions very seriously. Forming 'good' questions, that is, those which lead to opening of the territory under investigation and allow for an expansion in thinking, is an art. My hope is that in addition to the ideas you might take from the text, you may also develop something of the skill of inquiry by immersing yourself in a text which has an explicit intent of 'living the questions'.

To emphasize this intent, the book's structure itself is organized around questions perennially raised about leadership. In the background of these explicitly articulated queries which serve as the focus for each chapter, other, more shadowy ones lurk. 'Why in our contemporary context do we keep asking so many questions about leadership?' 'What does the asking of these questions reveal about who we are in our particular socio-historic moment?' 'How does reflecting on the "questioner" and why he or she is posing the question offer further insight into the nature of the phenomenon being investigated?' Ideally, the text will provoke many more explicit and emerging questions of your own from which you may rethink leadership.

\section{QUESTIONS TO RETHINK}

The next three chapters address ontological aspects about the nature of leadership. ${ }^{5}$ Rather than just taking for granted assumptions about the kind of phenomenon it is, they open this territory by exploring three key questions. Chapter 2 asks, 'Why are there so many different theories of leadership?'

This question is often directed towards leadership scholars by skeptical social scientists with the implied suggestion: 'given its lack of definitional clarity, how can leadership claim to be a "real" sort of thing, worthy of the large amount of scholarly attention paid to it?'

Where does this question come from in the first place? (Philosophy is very good at asking questions about questions.) I argue that this query arises from the concerns of a positivistic paradigm in which definitions can be 'objectively' agreed and component parts of things identified and measured. Furthermore, the chapter goes on to explore the possibility that the difficulty in 
defining leadership itself might be a helpful clue as to the kind of phenomenon it is. Ideas from phenomenology, such as the relevance of 'aspects' and 'sides' in describing entities as well as the distinction between 'wholes', 'pieces' and 'moments' are introduced to explain the lack of definitive accounts of leadership. In fact, the chapter ends by proposing that we may need more rather than fewer renderings of leadership in order to fully appreciate its impact on social systems.

Chapter 3 expands on this phenomenological exploration by wondering: 'Why is it so difficult to study leadership?'

A growing number of leadership theorists, including Peter Gronn (2002) in his study of distributed leadership within higher education and Mats Alvesson and Stefan Sveningsson (2003) in their study of leadership in high-tech firms, highlight the difficulties in pinpointing where or how leadership occurs within communities. Alvesson and Sveningsson conclude that leadership has a curious way of disappearing, both for leaders and for those who understand themselves to be led. Although ubiquitous in the way we construct our experience of organizations, leadership proves to be elusive under close examination. The chapter draws on the phenomenological notion of 'identity' to examine why its very elusiveness may be essential to its nature as a phenomenon. This argument is further explored through reference to the distinction Martin Heidegger (1962) draws between 'readiness-to-hand' and 'present-at-hand'. These ideas challenge us to be curious about the way in which the very difficulties associated with studying leadership themselves provide useful insight into its essence.

Chapter 4 introduces key ideas from Maurice Merleau-Ponty's thinking to explore the question, 'What goes on in the relationship between leaders and followers?'

We all know that leaders are not leaders without followers. The last ten years have seen a burgeoning of 'relational' leadership theories, the most prominent of which is probably Leader-Member Exchange theory (Gerstner and Day 1997; Graen and Uhl-Bien 1995). Although this theory has brought attention to the leader-follower dynamic at the heart of leadership, it does little to explore what really constitutes the 'in-between' space connecting leaders and followers. Mary Uhl-Bien (2006) in her article Relational Leadership Theory: Exploring the Social Processes of Leadership and Organizing, points to the lack of relational leadership theories which genuinely attend to this relationship as their focus. Is there a way to conceptualize this 'relation' itself, rather than the separate entities of 'leaders' and 'followers'? In this chapter, Merleau-Ponty's notions of 'reciprocity' and 'flesh' are introduced as constructions capable of providing a means for understanding the dynamic in-between space at the heart of leader-follower relations. 
Having explored these more general questions about the nature of leadership, the book considers new questions which were not explored in the first edition. In Chapter 5, Claire O'Neill draws from Merleau-Ponty as well as the more contemporary phenomenologist Drew Leider to explore how gender works within leadership relations. In particular she introduces the notion of the 'dys-appearing body', which deepens our understanding of how bodies which are considered 'other' to the accepted norm encounter particular challenges when leading. Chapter 6, written by Tayo Switzer critiques the usefulness of the Leadership Moment within the practice arena of organizational business consulting. This chapter provides helpful commentary on the ways in which the model both illuminates practice, but also ways in which it falls short of capturing the realities of organizational business life.

In Chapter 7, some of the ideas from Chapter 6 are more fully considered in new thinking I have done around leadership and power. Drawing from Michel Foucault's writings, this chapter aims to disrupt common assumptions about power and how it works within leadership relations. Chapters 8 and 9 look at two aspects of leading well from a moral perspective. Rita A. Gardiner draws from Hannah Arendt's work to examine what it means to lead responsibly, and in Chapter 9 I ask the question, 'How is it possible for leaders to lead wisely?'

In Chapter 10, Perttu Salovaara explores leadership's 'absences' by explicitly considering the 'incompleteness' of leading as it is so often framed: as an activity rife with accomplishment and victory. Perttu asks the question, 'What happens to the fullness of human experience, its brokenness and uncertainty, when it is left out of what we consider leading?'

The final chapter reflects on the journey the book has taken by posing the question, 'What has it meant to rethink leadership?' This chapter dwells on the key themes which have arisen from the intersection of leadership and philosophy. One of those themes, the distinction between 'leaders' and 'leadership', is worth introducing here as it will enable you to understand the starting point for the ensuing arguments.

\section{A NOTE ON TERMINOLOGY: 'LEADERS' AND 'LEADERSHIP'}

This book is primarily concerned with 'leadership', rather than 'leaders'. Leadership is seen to be a collective process, encompassing both those who would be known as 'leaders' and those who would be known as 'followers'. Additionally, I assume that these are not static labels and that leadership can readily pass between them so that leaders can act as followers and followers can act as leaders in certain circumstances. The experience of leadership is also assumed to emerge from particular social and historical contexts. This implies that individuals may enact very similar behaviors in different contexts 
and they may be interpreted as 'leaders' in some and not in others. In this way, just as leaders cannot operate without followers, they also cannot operate outside historical times and places. All of these ideas will be explained more fully in Chapter 2. However, it is important to alert readers to these assumptions at the outset of the text as they inform so much of the thinking within it. To put it simply, this book does not focus on the qualities, traits or abilities which 'leaders' may or may not exhibit. Instead, I conceptualize leadership as a collective process and seek to understand that process through applying philosophical ideas which by their nature aim to explicate experience from the 'inside out' rather than from an objective stance.

Laboring this distinction is important because it speaks to a fundamental purpose at the heart of this book. What has often passed as leadership scholarship has, on closer examination, been dedicated to understanding 'leaders'; those individuals who grab our attention amidst what is perhaps a much more complex intersection of contextual and personal factors. This one-pointed focus, I believe, allows limited scope for comprehending the full range of options available to anyone in an organizational system wishing to influence it in particular ways. Too often I have heard the complaint from participants on leadership development programs, 'I am only a middle manager; it is the senior managers who have the power to make this happen'. 'It is the leaders, over there, up there, who have the power to actually make a difference'.

One answer to this protest is represented in contemporary discourse by the idea that 'everyone can be a leader'. I suggest that understanding 'leadership' as a more complex interaction brings a more nuanced appreciation of that pronouncement. As a start, it means that the way in which the 'follower' role is taken up is highly implicated in the quality of leadership which emerges from collective action. More than that, the book aims to broaden our understanding of leadership as a phenomenon which goes beyond constructions of 'leaderfollower'. In doing so, it seeks to alert all of us working within organizational territories as well as studying them to the variety of possibilities available to all actors within hierarchical systems to initiate, influence or create significant instances of leadership.

My aspiration is that the ideas offered here might provide leadership scholars with additional conceptual breadth to reconsider the often hidden intricacies interacting whenever leadership occurs. The book is also written with those engaged in the practice of leadership, whether that be in organizational, community or family settings in mind, in the hope that they too might find ideas to underpin thoughtful and wise enactments of this aspect of collective activity. 


\section{SOME IDEAS ABOUT ENGAGING . .}

As indicated above, this book is written for two audiences. The first is the growing number of people studying leadership as a phenomenon in its own right. You may be an organization theorist or management academic who teaches leadership and is looking for an approach which throws new light on questions you have pondered yourself. You may be a student on one of the increasingly popular 'Leadership Studies' degree programs who is grappling with the myriad of leadership theories and how to make sense of them. Alternatively, you may be involved in leadership development in search of a way of deepening your understanding of some of the theoretical underpinnings of leadership as a practice and looking for alternative constructions to offer clients. The second audience comprises organizational or community leaders who are actively engaged in developing a depth of understanding about leadership. You may have already learned all you can through reading the victory narratives offered by successful corporate executives or autobiographies of exemplars such as Nelson Mandela or Mahatma Ghandi. You may be wondering yourself about the difference between what is written about leadership and your own experience of it.

Whatever your background, you do not have to be a philosopher or have philosophical training to follow the arguments that will be made in this book. The fact that you have picked up this text and read so far already indicates the requisite curiosity to experiment with a kind of thinking which might lead to a new comprehension of this aspect of organizational and community life. The resources you will need on this journey are a bit of inquisitiveness, the willingness to challenge your habitual assumptions about leadership, and perhaps most importantly, a sense of play. Although philosophy and philosophizing are often thought to be serious pursuits, in fact philosophers throughout the ages have engaged in 'mind play' to test the edges of their thinking possibilities. This is serious play, with the intention of exposing one's current limiting assumptions and expanding into new conceptual territories.

As mentioned previously, the book engages with philosophy in two manners. Firstly, it introduces key ideas developed by particular philosophers, such as Merleau-Ponty's notion of 'flesh' (1968) or Heidegger's work on 'dwelling' (1971), and suggests ways in which these concepts might enrich, challenge or reframe traditional understandings of leadership. Secondly, the mode in which the text is written itself reflects a method of philosophical inquiry. It often challenges the questions which are asked about leadership and wonders about the extent to which further insight can be gained by asking different questions. It calls into question the taken-for-granted assumptions which inform traditional ways of thinking about leadership. By these means I aim not only 
to provide new content relevant to understanding leadership but to encourage a radical approach to the very process of thinking about leadership.

Therefore, you will not necessarily finish reading this text with fully formed ideas of how to restructure your next research study or with a clear view of how to run a new and innovative leadership development program. Instead, I hope the ideas offered here will open up what has become a congested area of study and evoke a sense of spaciousness in those who read it. By introducing a novel way of engaging with existing leadership theory, the book will demonstrate how each rendering, whether it be 'distributed', 'servant', 'collective' or 'transformational', contributes to illuminating an important (but not sole) aspect of leadership's identity.

The book aims to be both intellectually stretching as well as practically relevant. In order to make this link, examples and stories from published studies as well as my own experience as a leadership scholar and developer are incorporated throughout the text. I am not setting out to deconstruct leadership and pronounce it dead or philosophically unjustifiable. Instead, the ideas presented here and the way in which they are offered are ultimately intended to provoke questions about why leadership has become the organizational panacea for our times. What does our current fascination tell us not only about leadership but about our particular historical and social moment and who we are within it? Have the ways in which we have traditionally thought about this phenomenon outlived their usefulness given the difficulties and complexities to which leadership must respond today? In disturbing our habitual patterns of thinking about leadership, this book aspires not only to provide new ways of thinking about it but also to foster renewed appreciation for this phenomenon and suggest a rationale as to why it might just justify the many thousands of words which have been written about it.

\section{NOTES}

1. Continental philosophy is a school of philosophy developed largely in Continental Europe during the twentieth century. It differs from 'analytic philosophy', which develops and applies the laws of rational logic by focusing on issues of meaning and the nature of lived experience. Analytic philosophy was largely developed in the United States and the United Kingdom.

2. For a comprehensive review of the range of different definitions of leadership, see J.C. Rost (1993), Leadership for the Twenty-First Century, Westport, CT: Praeger.

3. For instance, in his study of university presidents, Birnbaum (2000) found that transformational leadership was a very inappropriate kind of leadership approach to use when leading academic communities. See Management Fads in Higher Education: Where they Come From, What they Do, Why they Fail, San Francisco, CA: Jossey-Bass.

4. For some, Continental philosophy and 'phenomenology' are synonymous. I am distinguishing the two terms and conceiving Continental philosophy as thinking 
which encompasses phenomenology, existentialism, structuralism and other philosophical ideas primarily developed by European thinkers.

5. Ontological questions are questions about the nature of a thing's 'being'. Ontological questions about leadership are those concerned with the kind of thing leadership is, that is, is it something we can easily see, is it constructed from the interaction of people's perceptions, is it located within a person? All of these questions will be addressed more fully in Chapter 2 . 